\title{
Memory as a Common Asset. Algorithmic Generative Representations for the Reconstruction of the Community Identity after the Earthquake
}

Giuseppe Amoruso

Polina Mironenko

\section{Abstract}

After a calamity, a community wonders about on which common assets to found the reconstruction and therefore its future identity. The study introduces an innovative generative simulation protocol that draws typological and parametric representations of reconstruction scenarios according to the masterplan and the recommendations for colour, materials and architectural lexicon and also socio-economic issues.

The working strategy starts from the morphological tuning between building and living in respect of maintaining the place character. The townscape is the result of generative algorithmic representations for the city of Amatrice; the protocol proposes reconstruction models according to the architectural and environmental town pattern book. The graphic document typologically summarizes the key elements of the environmental character; it is possible to parameterize these data and build a tool for the generation of urban digital models to fix the block reconstruction. The need for this operational tool arises considering the numerous failures of reconstruction practices after recent earthquakes and rebuilding the city not only as a technical and technological response but also as a social responsibility to include commons and therefore memory and landscape.

Keywords

commons, historic urban landscape, generative algorithmic simulation, heritage BIM, Amatrice.

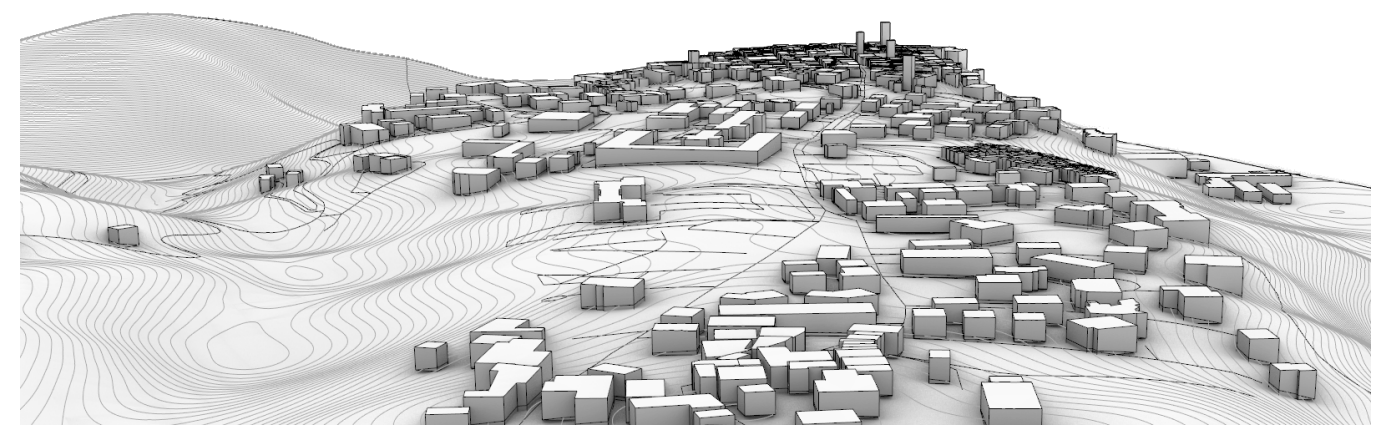




\section{Introduction}

It takes an incredible amount of time, energy, culture, resources, and people to build a city. Even more to make it beautiful, a continuous process of architectural tuning that make a settlement the best place to live in. But unfortunately, it only takes a few seconds to destroy it, after the earthquake. Despite this fragile condition, cities have always been destroyed and then rebuilt. Organic reconstruction is the natural answer according to the several references and lessons from history, but unfortunately not the most frequent in the Italian recent earthquakes.

The research deals with the reconstruction process of Italian centres affected by the 2016 earthquake and focuses the application on the ruined historic centre of Amatrice and the challenge to maintain alive its authentic character rebuilding a social community. Memory as a common asset is related to the Faro Convention (2005) that introduced two innovative concepts:

- cultural heritage is a collection of resources inherited from the past which people identify, independently of ownership, as a reflection and expression of their constantly evolving values, beliefs, knowledge and traditions.

- heritage community that consists of people who value specific aspects of cultural heritage which they wish to sustain and transmit to future generations.

According to these principles, the research main outcome is the typological and parametric representation identity character based on algorithmic simulation and the generation of 3D models of the blocks as harmonic tuning of different architectural and urban design issues.

\section{Understanding and representing the cultural landscape as a common good}

The purpose of the project is to oppose the phenomena that impose material destruction by recalling those immaterial values such as the universal concepts summarized by the beauty of a place. Memory as a common good means thinking about the landscape in a positive way by fighting the dominant iconoclasm and considering the protection of the environment, landscape and cultural heritage, as common goods for which to exercise political action and the recognition of the rights of a community. Its destruction or reconstruction reveals that common landscape or beauty can symbolize the civilization that created it, but also its failures.

The expression 'common assets' derives from the theory exposed by Elinor Ostrom that presented the result of a continuous examination of the nature of the commons. The work emphasized the role of public choice on decisions influencing the production of public goods and services, involving local communities in the continuous challenge to craft their landscape for the benefit of a collective, widespread, and shared identity [Ostrom 1990]. In her foundation work, Ostrom characterizes the rules that advance effective results to handle conflicts of interest and introduces three influential models of commons, making reference to past researches and writings. The first model is the 'tragedy of the commons' to symbolize the degradation of the environment to be expected whenever many individuals use a scarce resource in common. According to Aristotle that long ago observed that "what is common to the greatest number has the least care bestowed upon it. Everyone thinks chiefly of his own, hardly at all of the common interest" (Politics. Book II, ch. 3).

Our Codice dei beni culturali e del paesaggio makes the landscape a property belonging to the public and destined for use by the community but the landscape asset is in any case an exceptionality, something that stands out and shines for its value and its singularity. The landscape assets are an integral part of the cultural heritage; as such they must be protected and valued in order to "preserve the memory of the national community and its territory and [...] promote the development of culture" $(I, I, 2)$. The landscape is certainly an asset, but it can also be considered common, including intangible values and its material expressions. Considering the inclusion of the landscape among the common goods, the most suitable regulatory tool is the European Landscape Convention. The territory is a whole covering 
natural, rural, urban, and peri-urban areas; landscapes that may be considered outstanding as well as every day and degraded landscapes. Another issue is the role of knowledge: "The identification, description and assessment of landscapes constitute the preliminary phase of any landscape policy. This involves an analysis of morphological, archaeological, historical, cultural and natural characteristics and their interrelations, as well as an analysis of changes" (fig. I).

Salvatore Settis highlights that, together with cultural heritage, the landscape is an active part of that connective tissue that surrounds us and surrounds us, and whose diffusion throughout the territory is abundant and widespread [Settis 2017; Settis 2010]; this statement marks a noteworthy difference with the text of the European Landscape Convention which already from the Preamble recalls that: "The landscape is everywhere [...] and again: "this Convention [...] concerns both landscapes that can be considered exceptional, and landscapes of everyday life and degraded landscapes". The research proposes the integration, in decision-making processes, of visualization models based on repertoires, high-iconic databases and predictive simulations. Local identity as common good means to define the local character documentation toolkit: urban pattern analysis, construction techniques and materials, environmental and tonal characteristic in relation to a sequence of landscape units that constitute the urban habitat.

In the UNESCO Recommendation on Historic Urban Landscape, article IV, a series of innovative tools are presented: "The approach based on the historic urban landscape implies the application of a range of traditional and innovative tools adapted to local contexts. Knowledge and planning tools should help protect the integrity and authenticity of the attributes of urban heritage. They should also allow for the recognition of cultural significance and diversity and provide for the monitoring and management of change to improve the quality of life and of urban space. These tools would include documentation and mapping of cultural and natural characteristics. Heritage, social and environmental impact assessments should be used to support and facilitate decision-making processes within a framework of sustainable development". Landscape can be described as a "common visual good" [Prieur 2006, p. I4] therefore its phenomenological value is absolutely to be investigated in its characteristics, as in this research it has been done since its early stages.

Fig. I. Algorithmic modelling with Grasshopper and Elk to generate the Digital Ground Model of Amatrice and a series of visualization and scenarios from open source dataset.

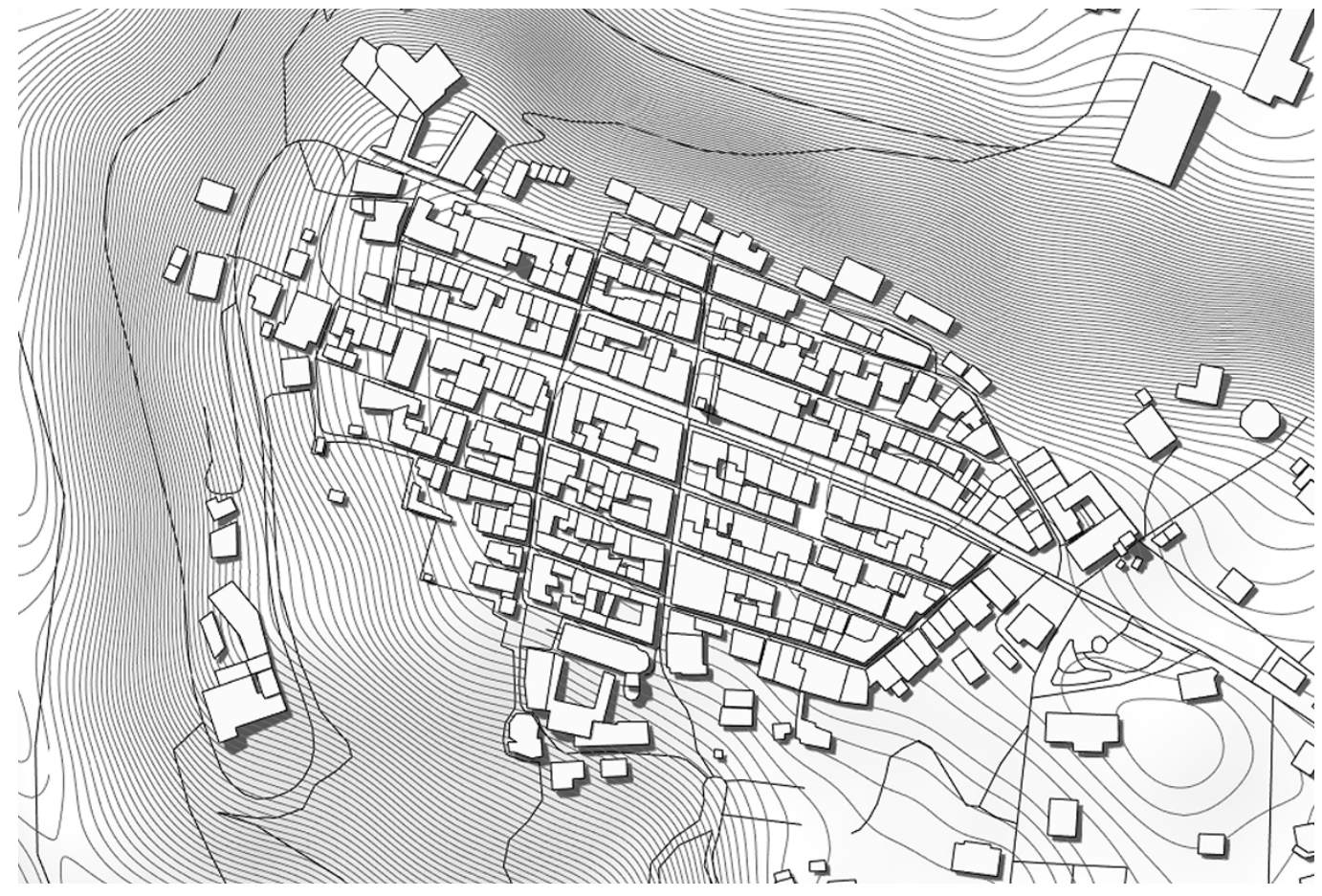


Maintenance of place character means simulate and visualize the typological, aggregative and functional solutions in respect of the regeneration of the social value of the places how it is expected by the community (fig. 2).

In the first phase of the research the main outcome was the release of the Codice di Amatrice: it's a pattern book that collects drawings and graphic illustrations of local traditional architecture and informs the best building practices. The pattern book is elaborated block by block according to the survey of the local landscape: the townscape is decribed by a transect based on a sequence of environmental units, from natural to urban core districts. The code includes also the graphic description of the architectural lexicon and of the construction techniques (figs. 3, 4).

The local character study identifies the most important features of different area, key views from and through the environment. It sets out some key design and conservation principles particularly relevant to the historic centre and makes suggestions where future improvement initiatives could be. Missing data and limited availability of surveys was managed making reference to territorial data collection from open source dataset while numerical and vector data and territorial images were grasped from opensource platforms.

The released pattern book is not prescriptive because it provides town planners, architects and builders with a useful resource of typologies and details for the design of urban space and buildings. It is intended to guide and strengthen the built character of the town, respecting the building code and the availability of local resources and building materials.

\section{Generative algorithmic reconstruction and representations for the city of Amatrice}

In Amatrice the earthquake had particularly disastrous effects and the site after the demolitions is totally unbuilt. For this reason, the proposal for the reconstruction workflow starts from the generative algorithmic modelling building typologies and façade types from masterplan and colour plan.

Predictive simulations based on algorithms of instant modeling for drafting territorial and urban models [Calvano, Guadagnoli 2016] are used to propose reconstruction scenarios and estimate economic management issues according to development and demographic forecasts elaborated a series of digital block models.

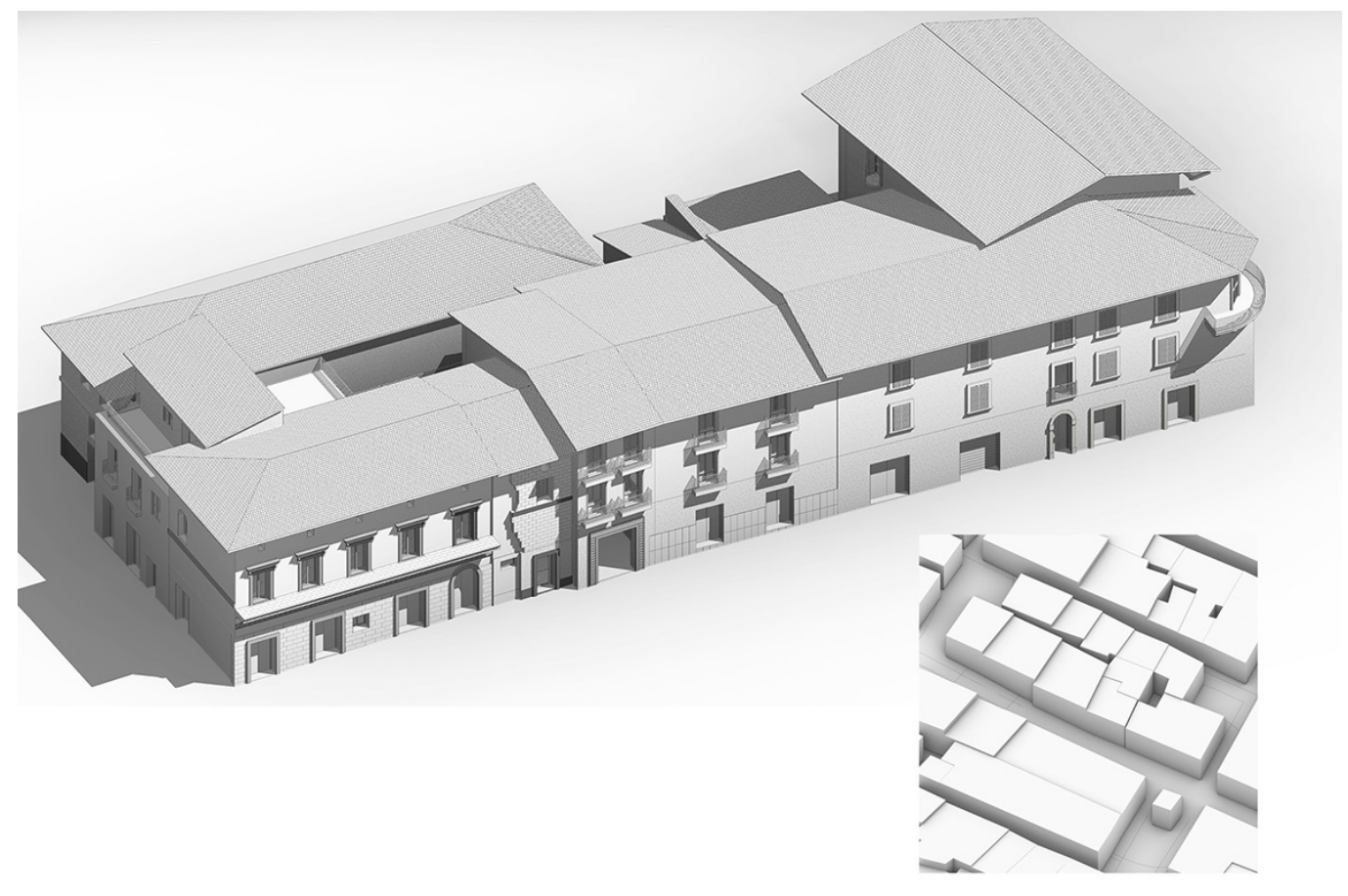


Fig. 3. The Pattern Book first sets out to identify some of the key patterns of urban form and public space in the historic

Amatrice The graphic

Amalysis points out the

analysis points out the

scarious character of the typologies.
Fig. 4. The Pattern Book of Amatrice sets out an analytical study of the massing scale. proportions and details of individual buildings, to promote an organi reconstruction of the town, with appropriate architectural and urban tuning.

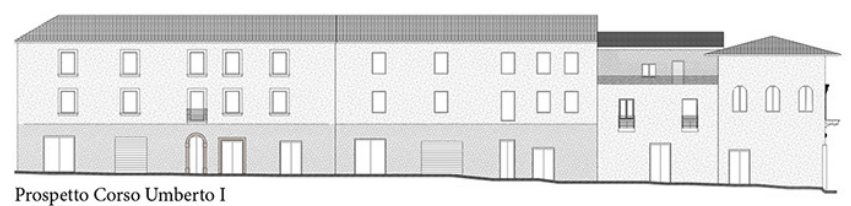

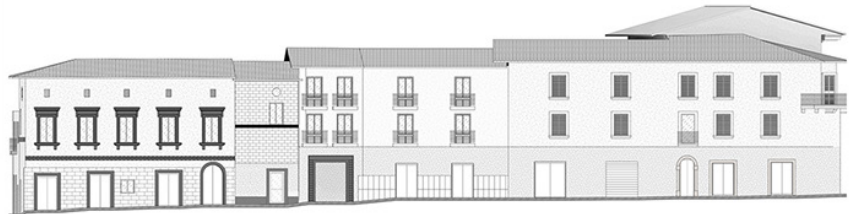

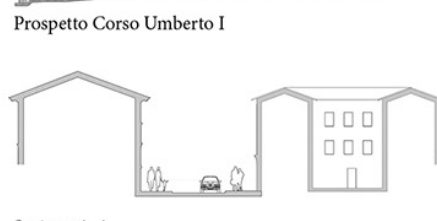

Sezione A-A
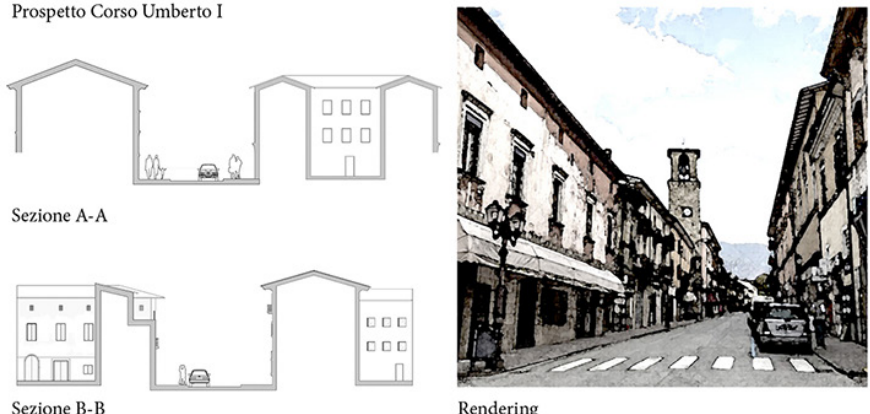

Rendering
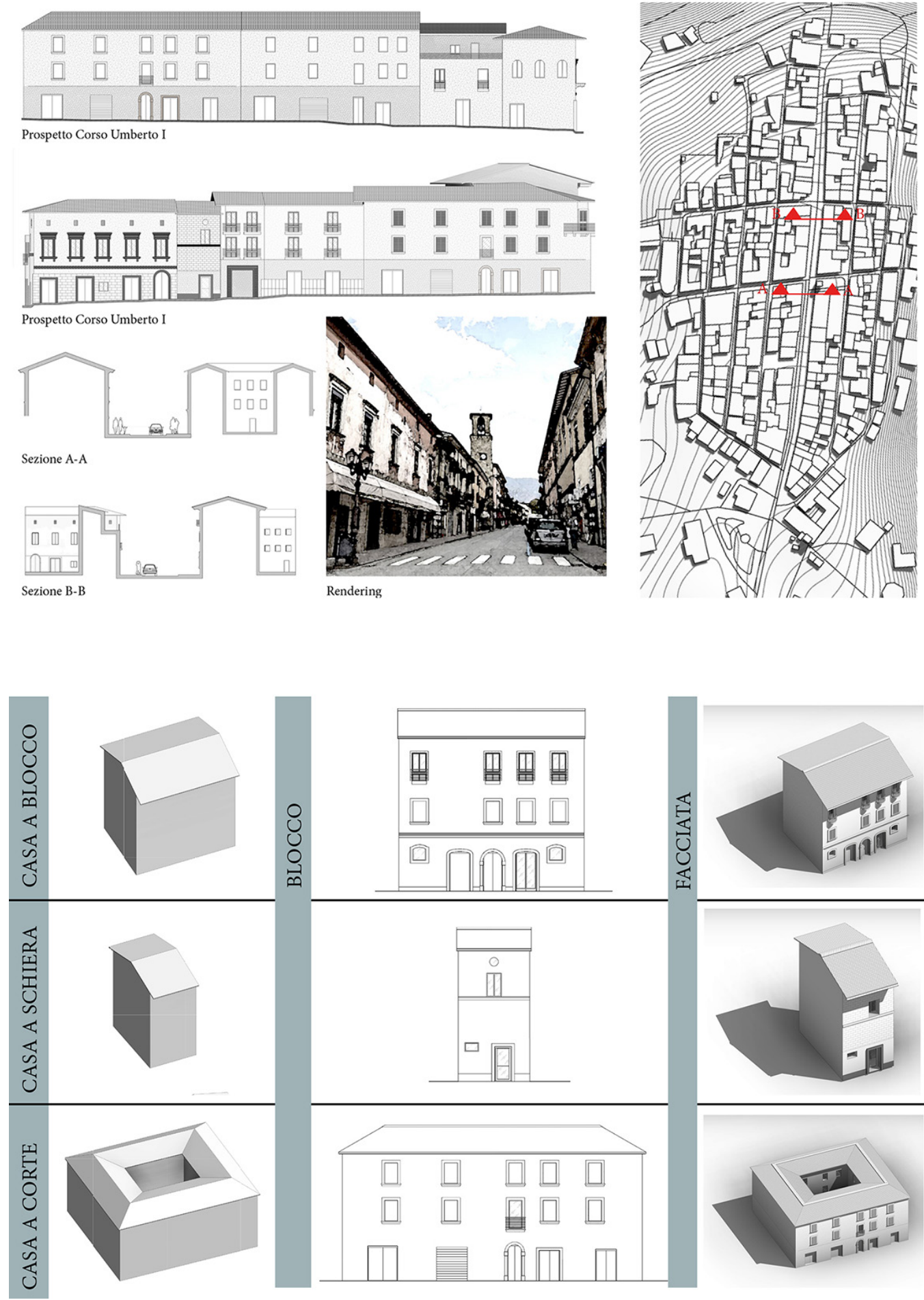
The research presents an innovative protocol for territorial and urban simulation that produces the 3D model of the minimum intervention unit after the release of the reconstruction plan.

The methodology follows a three-phase process for historic urban landscape documentation: analytical data collection and classification of urban typologies and architectural lexicon, representation of enviromental character and generative modelling of architectural composition, materials, patterns, textures, and chromatic dominants within for each building and block. The site was studied recording each building, master models, and drawing the whole block elevation, derived models, in order to enhance the understanding of chromatic landscapes and the variability of tones and building techniques. The documentation process was applied to the main street landscape, Corso Umberto I, where it is usual to analyse and classify a more complex variety of artefacts from a typological point of view: age, size, geometry, façade technology, lexicon, textures, colour gradient and dominants façade semantics.

$3 \mathrm{D}$ representation of ground's surface were created from a terrain's elevation open data exploiting high quality SRTM data: GeoTiff images, grey scale raster formats that tile the whole planet, from online dataset that contain also metadata of geographical references with which to reconstruct the earth's surface. (fig. 5) 3D maps included also the individual blocks, according to different building types, to rebuild the townscape as local identity and common asset.

After the data and information collection, Amatrice was reconstructed with the CAD software Rhinoceros associated with Grasshopper, a visual programming language and environment. This plugin is primarily used to build generative algorithms and many of its components create 3D geometry, but tools may also contain other types of algorithms including numeric, textual, audio-visual and haptic applications. The algorithmic modelling with Grasshopper introduced a set of tools, Elk, to generate maps and topographical surfaces using open source data from OpenStreetMap.org and USGS. OpenStretMap.org is an open/crowd sourced website of mapping data. It allows to export XML formatted data of a selected area and then Elk will organize and construct collections of point and tag data so that it is possible to create curves and other Rhino/Grasshopper geometry. Through this set of integrated tools and also data on building features, it was generated the Digital Ground

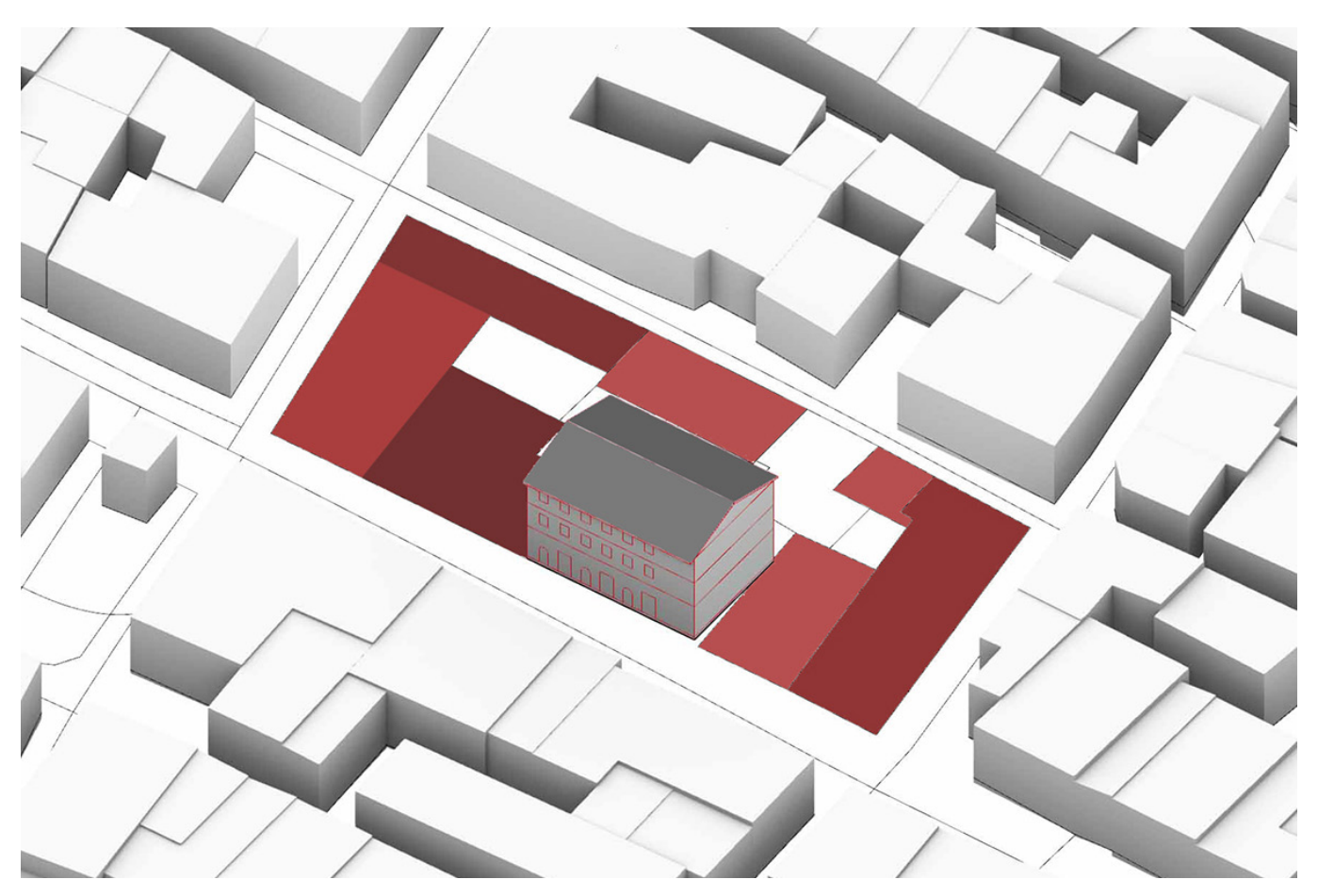


Fig. 6. 3D visualization of the sample building in Corso Umberto I. according to the urban typologies parameters (top, left) and the

complete al rorithm and complete aldorithm and gentiv) sequence (bottom) that figures out floor and fit the building to each individual plot. floor and fit the building
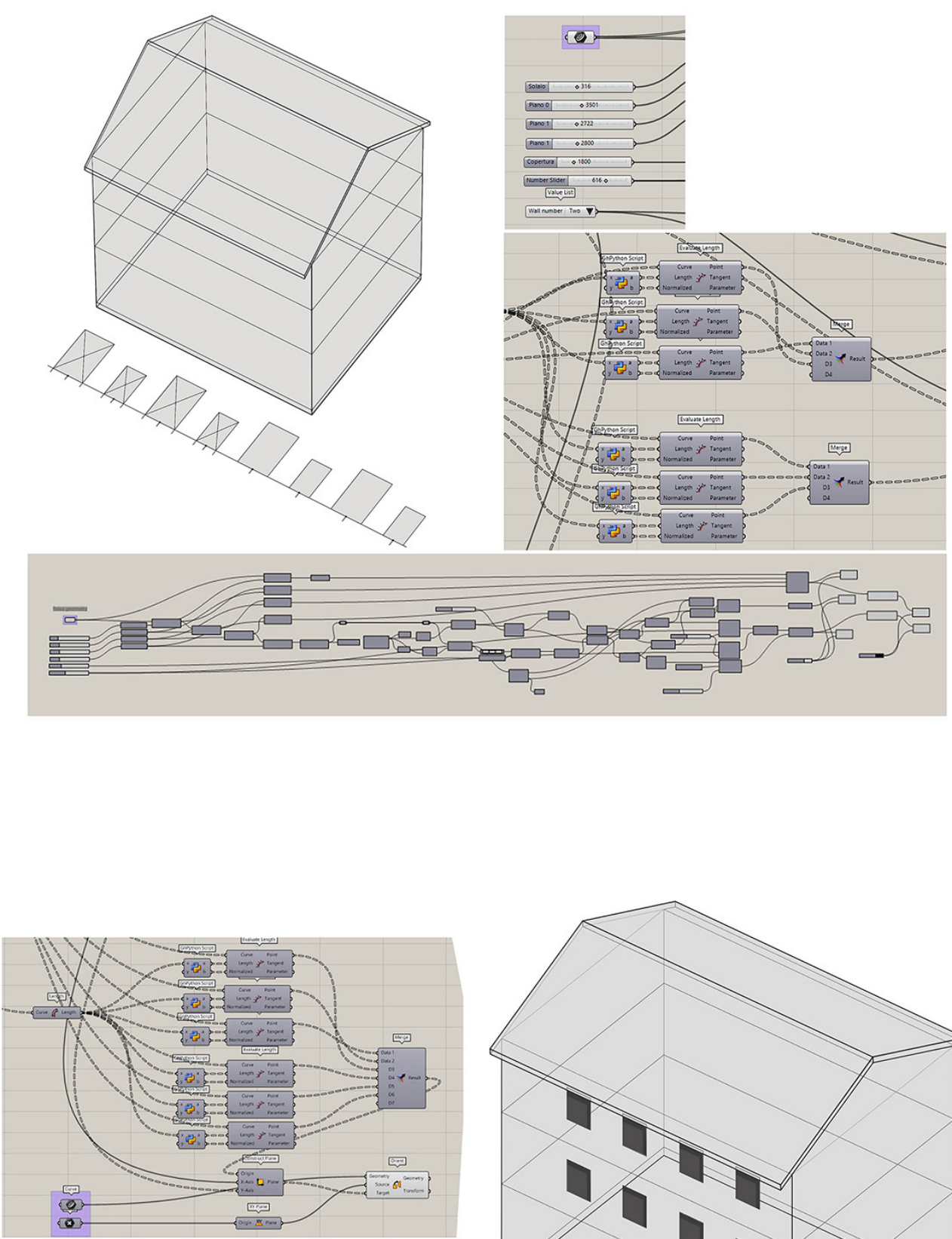

Fig. 7. 3D visualization of the sample building in Corso Umberto I composition and opening parameters (right) and the algorithm and generative sequence

(left) that figures out the 3D model, floor by floor fitting the architectural fitting the architectura façade.

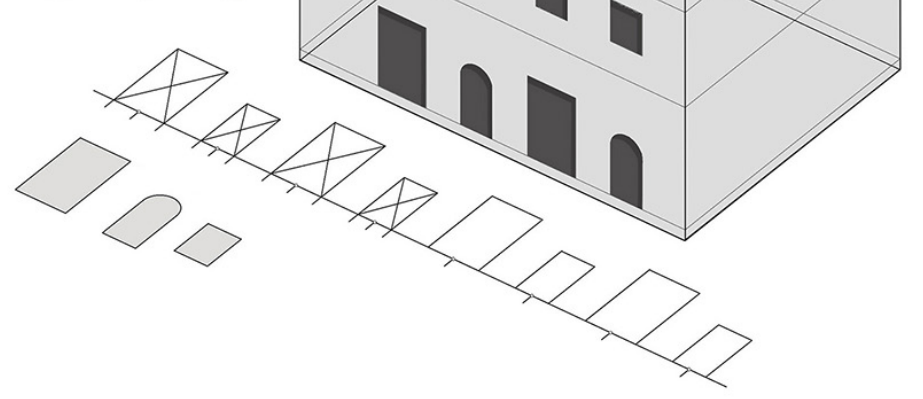


Fig. 8.3D visualization of Corso Umberto according to the façade composition and building composition (top) an extraction of the 3D model to be sampled and designed according to the façade type and the colour plan regulations (bottom).
Model of Amatrice and a series of visualization and scenarios for each block according to state of the art before the earthquake.

The algorithm generates the 3D model based on the urban typology for each batch of the seismic aggregate. Once morphological, volumetric, geometric and architectural parameters have been defined, the algorithm produces a model that automatically adapts to the shape of the lot and allows you to propose different scenarios considering the number of residents expected and the consistency of the rooms to respect the qualities of the apartments before of the seismic event. It is possible to modify the parameters in a flexible way according to the needs and the expectations of the reconstruction plan, maintaining the general character of the places in relation to the typologies and the architectural lexicon but also considering that interiors will be retrofitted by the need to adapt them to modern standards and design regulations and to the resistance criteria of seismic regulations.

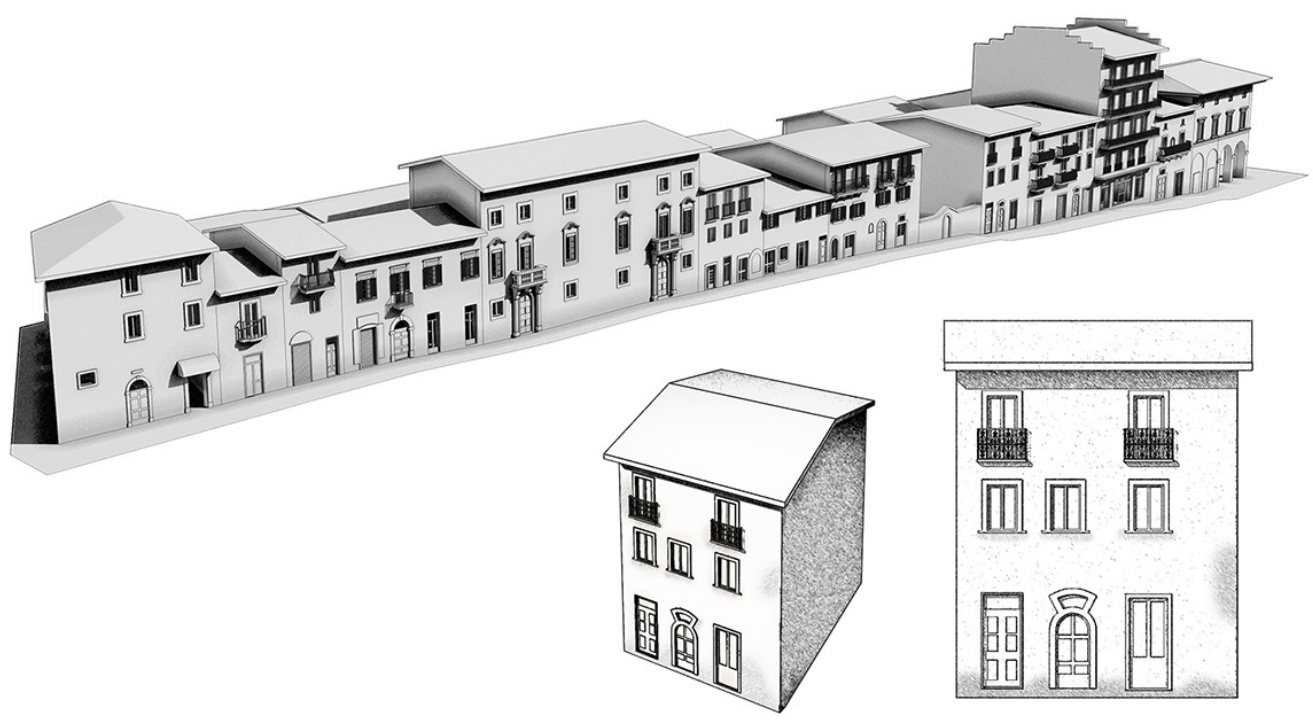

The algorithm models the urban shape, for example by including the number of floors and their height to ensure environmental comfort and energy performance, but considering the type of roofing, it allows a harmony between architectural characteristics and image of the places. Through this procedure it is possible to represent the plan with the typologies distribution, which can also have variants and be updated automatically according to future needs (figs. 6, 7).

The algorithm that generates the composition of the openings on the facade allows us to adapt the types of holes in relation to the repertoires included in the pattern book and the regulations contemplating different configurations, geometric relationships and construction characteristics.

The algorithm calculates and draws the composition of the facade and then applies it on the model of the building according to the urban typology, the type of facade as defined by the color plan, the libraries of the decorative elements, materials and colors for walls, woods and irons (figs. 8, 9).

The model generated by Rhino/Grasshopper offers, according to the different combinations and configurations, an interoperable architectural parametric model within the BIM environment of the Archicad software. This connection allows us to manage the color plan, and 
therefore manage the quality and environmental characteristics, in Heritage BIM mode, and produce as built libraries of architectural elements, colors and materials.

The Heritage Building Information Modelling will integrate the simulations from generative modeling and develop the semantic representation and the typological documentation of building libraries: the HBIM model for each block of the town centre (the seismic aggregato) will be released. This working tool is the pillar of the research strategy, to be developed in detail and to be tested and it will be also a way to support the decision-making process validating the design proposal for each aggregato as designed, at the level of private enterprise. The digital BIM will allow for the virtual testing and simulation of different solutions for the same plot or block (intended as the aggregato, the minimum intervention unity), as well as the comparison and checking of the impact of new buildings, blocks, and interventions, thus helping to ensure the preservation of Amatrice's unique sense of identity and place. The BIM libraries could be 3D-printed and exhibited during technical sessions and community consultations. It will be an interactive tool providing information, visual references, and supporting evidence to aid the reconstruction process and associated decision-making (fig. I0).

Fig. 9. Visualization of Corso Umberto according to the colour plan regulations.

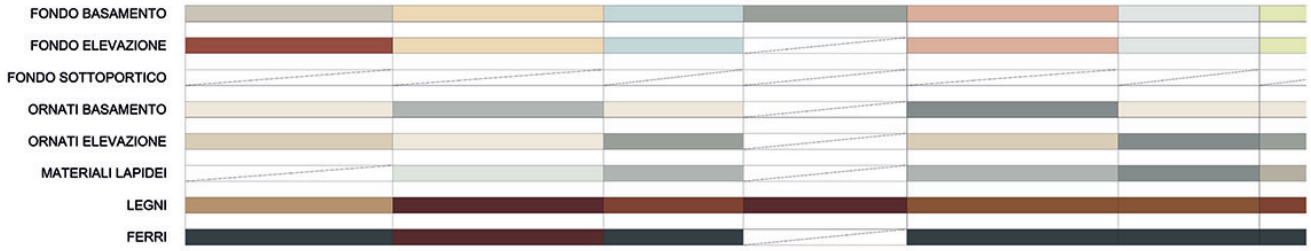

M.⿴囗十ा

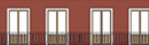

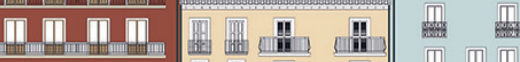

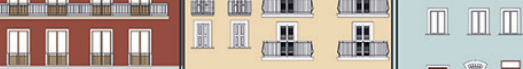

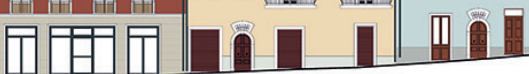

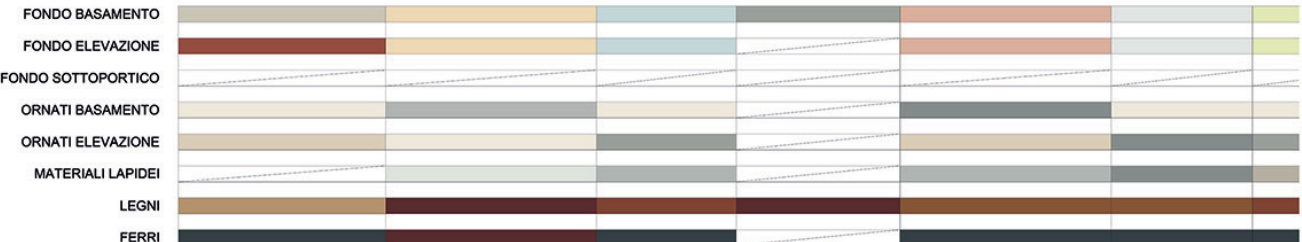

\section{Conclusions}

Future developments have to promote an innovative beauty policy which instead makes it an instrument of knowledge of the world and also of cities, of historical awareness, of ethics of citizenship, of substance of the common good. If a landscape is a common good, it belongs to everyone as long as it is recognized that its first point of reference is made up of the local communities that manage it according to shared and cooperative rules. The research proposed a methodological model of reading, interpretation and narrative of the local identity creating a generative modelling process to visualize and assess the reconstruction scenario maintaining the place character. The process has been tested on the information and documentation systems of the historic urban landscapes of Amatrice. The algorithmic design is the critical and key issue of this research stage and it will require a long phase of testing including all the issues and the kind of regulations the reconstruction plan will impo- 
Fig. 10.2D visualization of the façade composition, architectural lexicon, and colour palette according to the colour plan regulations.
se.The ultimate goal is to develop the framework as a place-identity toolkit for communities and places and to generate design coding strategies providing an efficient pipeline from townscape documentation to the management of the reconstruction.
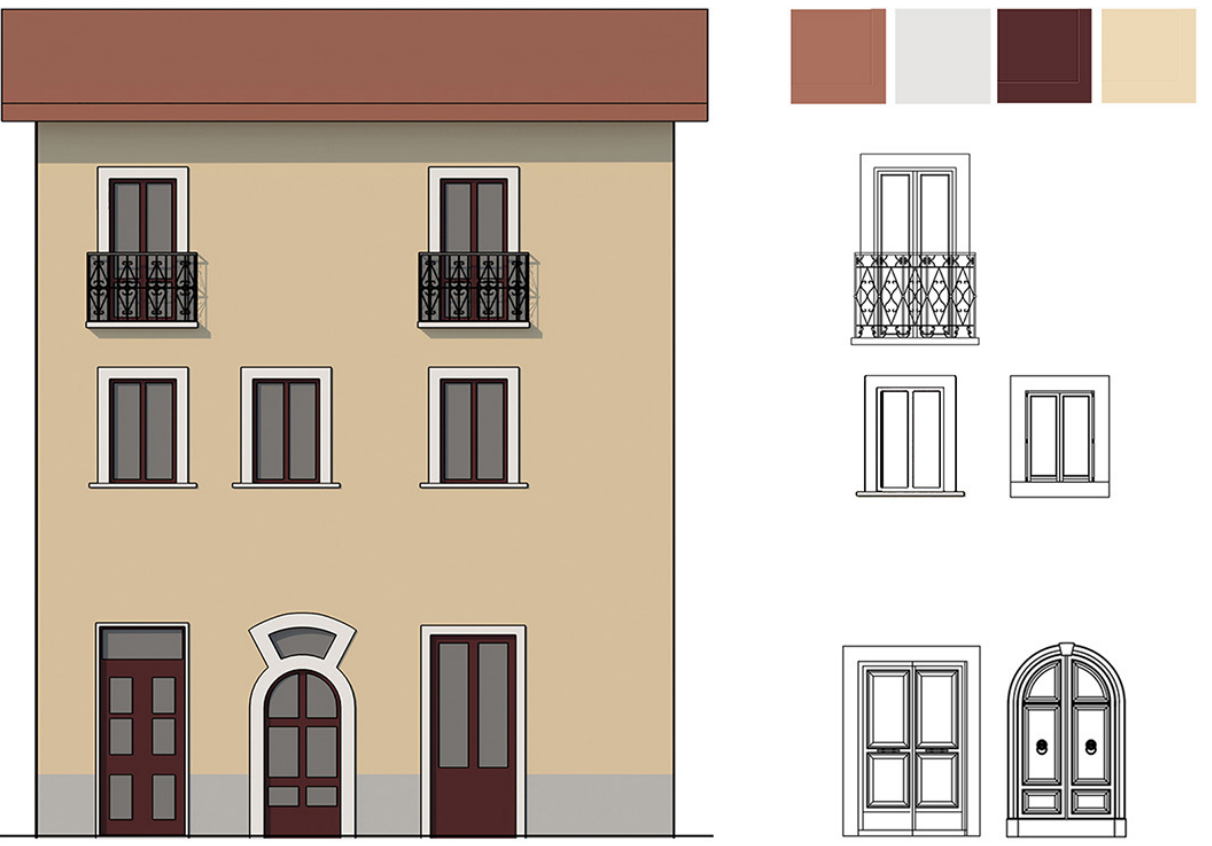

\section{Acknowledgments}

This work is part of the international research project: Regenerating Amatrice. The resilience of local identity funded in 2017 by the Prince's Charitable Trust and promoted by the International Network for Traditional Building, Architecture \& Urbanism that works under the patronage of its founder HRH the Prince of Wales. Giuseppe Amoruso is coordinating the research addressing the methodology, designing the process contents and validating the algorithm and the outcomes and also edited the present essay including the illustrations; Polina Mironenko elaborated the simulations integrating multiple data sources and drafted the generative algorithm, the computational models and the graphic materials.

\section{References}

Michele Calvano, Francesca Guadagnoli (2016). Ricostruzione 3D della città di Amatrice. Una operazione di 'instant modeling'. In DisegnareCon. Musei virtuali dell'architettura e della città, 9, 17, 2016, pp. 7.I -7.9.

Ostrom Elinor (1990). Governing the commons: the evolution of institutions for collective action. Cambridge: Cambridge University Press (trad. it. Governare i beni collettivi,Venezia: Marsilio, 2006).

Prieur Michel (2006). Landscape and social, economic, cultural and ecological approaches, in Council of Europe, Landscape and Sustainable Development. Challenges of the European Landscape Convention. Strasbourg: Council of Europe Publishing, pp. I I-28.

Settis Salvatore (2010). Paesaggio, Costituzione, Cemento. Torino: Einaudi.

Settis Salvatore (2017). Cieli d'Europa. Cultura, creatività, uguaglianza. Torino: Utet.

\section{Authors}

Giuseppe Amoruso, Politecnico di Milano, giuseppe.amoruso@polimi.it

Polina Mironenko, Politecnico di Milano, polina.mironenko@polimi.it

To cite this chapter. Amoruso Giuseppe, Mironenko Polina (2020), Memory as a common asset. Algorithmic generative representations for the reconstruction of the community identity after the earthquake. In Arena A., Arena M., Brandolino R.G., Colistra D., Ginex G., Mediati D., Nucifora S., Raffa P. (a cura di). Connettere. Un disegno per annodare e tessere. Atti del $42^{\circ}$ Convegno Internazionale dei Docenti delle Discipline della Rappresentazione/Connecting. Drawing for weaving relationships. Proceedings of the 42th International Conference of Representation Disciplines Teachers. Milano: FrancoAngeli, pp. I528-1537. 